\title{
Mercury and selenium in developing and mature fruiting bodies of Amanita muscaria
}

\author{
Anetta Hanć ${ }^{1}$ - Alwyn R. Fernandes ${ }^{2}$ • Jerzy Falandysz $z^{3,4,5}$ (Di Zhang ${ }^{5}$
}

Received: 18 July 2020 / Accepted: 1 June 2021 / Published online: 21 June 2021

(C) The Author(s) 2021

\begin{abstract}
Both mercury $(\mathrm{Hg})$ and selenium (Se) occur in many mushroom species, but the morphological distribution of these elements during different developmental stages of the fruiting bodies is not known. Although Amanita muscaria can be consumed after suitable processing, they are often ignored by mushroom foragers, leaving an abundance for investigative study. Multiple specimens in each of six developmental stages (button to fully mature) were collected in excellent condition during a single morning from the same forested location and composited. With an average of 30 specimens per composite, and low temporal, spatial, and measurement uncertainty, the data are likely to be representative of the typical concentrations of $\mathrm{Hg}$ and Se for each developmental stage. $\mathrm{Hg}$ (range $0.58-0.74 \mathrm{mg} \mathrm{kg}^{-1}$ dry weight cap; 0.33 to $0.44 \mathrm{mg} \mathrm{kg}^{-1} \mathrm{dw}$ stipe) and Se (range $8.3-11 \mathrm{mg} \mathrm{kg}^{-1}$ $\mathrm{dw}$ cap; 2.2 to $4.3 \mathrm{mg} \mathrm{kg}^{-1} \mathrm{dw}$ stipe) levels were observed to vary during the developmental stages, and the variability may relate to the demands in growth. In common with some other species, the lower stipe concentrations may be consistent with nutrient/ contant transport and support functions. Both $\mathrm{Hg}$ and Se levels were lowest during periods of maximum sporocarp growth. Selenium occurs at almost an order of magnitude greater levels than $\mathrm{Hg}$. Due to its role in mitigating the effects of $\mathrm{Hg}$ toxicity, this property is of significance to those who consume the species either for nutritional, medicinal, or recreational purposes, although the losses of both these elements during processing are not known.
\end{abstract}

Keywords Fly agaric $\cdot$ Ectomycorrhizal $\cdot$ Mushrooms $\cdot$ Methylmercury $\cdot$ Seleno-compounds $\cdot$ Sporocarp development

\section{Introduction}

Amanita muscaria (L.) Lam. is an ectomycorrhizal fungus, popularly and better known worldwide as the fly agaric

\section{Responsible Editor: Philippe Garrigues}

Jerzy Falandysz

jerzy.falandysz@gmail.com

1 Department of Trace Element Analysis by Spectroscopy Method, Adam Mickiewicz University, Umultowska 89b, 61-614 Poznań, PL, Poland

2 School of Environmental Sciences, University of East Anglia, Norwich NR4 7TJ, UK

3 Environmental Chemistry and Ecotoxicology, University of Gdańsk, Gdańsk, Poland

4 Environmental and Computational Chemistry Group, School of Pharmaceutical Sciences, University of Cartagena, Zaragocilla Campus, 130015 Cartagena, Colombia

5 Medicinal Plants Research Institute, Yunnan Academy of Agricultural Sciences, Kunming 650200, China mushroom. It was notorious in earlier decades for its hallucinogenic properties - all parts of the mushroom have psychoactive properties, caused by some of its related constituents, ibotenic acid, muscarine, muscazone, and muscimol (an unsaturated cyclic hydroxamic acid) which may be more abundant in the flesh just below the cuticle. Historically used in shamanistic rituals in some northern European and Asian cultures, A. muscaria has also been reportedly (Guzmán 2008) used in traditional Mexican medicine as a diuretic and purgative and for the treatment of epilepsy. The mushroom is less well known as a food that is foraged or collected for recreational purposes. Detoxification is achieved by boiling of the flesh (a couple of times) with rejection of the water (Rubel and Arora 2008). It is consumed in parts of Europe, North America, and Asia, particularly Japan, where it may be consumed after salting and pickling (Phipps et al. 2000).

Amanita muscaria is native to coniferous and deciduous forests across the temperate Northern Hemisphere but is also found in other regions in the Southern Hemisphere (Hawkeswood 2006) where it was inadvertently introduced through pine and other plantations. It exists in biochemical 
symbiosis with the roots of conifers including pine, spruce, fir, birch, and cedar, but the mycorrhizal associations may be tripartite, involving other fungal species as well. It was reported (Yun and Hall 2004) that rhizomorphs of Boletus edulis Bull. were often observed closely intertwined with Amanita, forming composite mycorrhizas which may facilitate the flow of nutrients between the two species.

Mushrooms, in general, are known to bio-concentrate a whole range of metals and metalloid elements, some of which have sometimes been used as indicators of local pollution as they reflect pollutant distributions in the substrate. In ectomycorrhizal species such as Amanita, metallic and metalloid elements may be actively or passively absorbed by the mycelium from the surrounding soil or substrate. The build-up of heavy metals is undesirable but not all elemental accumulations are harmful, and some have essential physiological functions in the flesh of mushrooms. Potassium, for example, functions as an intracellular cation for osmotic regulation of the water content and as a co-factor in enzymes. As part of the biochemical symbiosis in Amanita, the absorbed trace elements are used by the mycelium but may also be shared with the ectomycorrhizal symbiont(s). In return the fungus obtains access to photosynthesis products, e.g., simple carbohydrates. Forest ecosystems have a high diversity of mycorrhizal associations and are subject to complex multi-species food chain networks (Luo et al. 2014; Van der Heijden et al. 2015).

This characteristic of sourcing nutrition from the surrounding soils or substrate bears an unfortunate side effects; it makes mushrooms vulnerable to contaminant uptake. In common with many species of fungi that grow in habitats that are contaminated with mercury, either of geogenic or anthropogenic (mining or other industrial) origins, A. muscaria efficiently bio-concentrates $\mathrm{Hg}$. Reported bioconcentration factors (BCFs) were in the range of 8.3 to 51 in the caps and from 4.1 to 28 in the stipes (Falandysz et al. 2007; Lipka et al. 2018), but several other Amanita spp. in Canada showed lower BFCs of 3.1 (caps) and 1.7 (stipes) (Nasr and Arp 2011). Fischer et al. (1995) noticed a higher potential of A. muscaria, collected from a former cinnabar mining site, to bio-concentrate methyl mercury (MeHg) (BCFs 3.0-10) relative to inorganic $\mathrm{Hg}$ (BCF was $0.48-1.0$ ), which was associated to the humus (organic) content of the soil layer.

Both inorganic mercury and $\mathrm{MeHg}$ occur in foods in varying amounts, with relatively high levels in foods of marine and animal origin (EFSA 2012). Inorganic Hg is highest in terrestrial foods such as wild mushrooms. Some reported $\mathrm{Hg}$ dry weight (dw) concentrations (Falandysz et al. 2015; Melgar et al. 2009; Seeger 1976), for example, of the popular genus Boletus were:

- Up to $22 \mathrm{mg} \mathrm{kg}^{-1} \mathrm{dw}$ in the caps and $8.4 \mathrm{mg} \mathrm{kg}^{-1} \mathrm{dw}$ in stipes of pooled fruiting bodies of $B$. bainiugan.
- $5.7\left(1.0-17 \mathrm{mg} \mathrm{kg}^{-1} \mathrm{dw} ; \mathrm{n}=8\right)$ in whole $B$. edulis with caps showing $1.1 \pm 1.4$ to $7.6 \pm 3.1\left(0.02-14 \mathrm{mg} \mathrm{kg}^{-1} \mathrm{dw}\right)$ and stipes from $0.82 \pm 0.71$ to $3.8 \pm 1.8(0.03-6.7 \mathrm{mg}$ $\mathrm{kg}^{-1} \mathrm{dw} ; \mathrm{n}=173$ ).

- B. pinophilus concentrations were $4.5 \pm 5.0 \mathrm{mg} \mathrm{kg}^{-1}$ $\mathrm{dw}$ (in hymenophore $6.9 \pm 8.3 \mathrm{mg} \mathrm{kg}^{-1} ; \mathrm{dw} \mathrm{n}=13$ ).

- B. reticulatus showed up to $4.4 \pm 1.3 \mathrm{mg} \mathrm{kg}^{-1} \mathrm{dw}$ in caps and up to $2.5 \pm 0.9 \mathrm{mg} \mathrm{kg}^{-1} \mathrm{dw}$ in stipes $(\mathrm{n}=15)$.

Although much of the terrestrial $\mathrm{Hg}$ in mushroom habitats is inorganic, it is well-known that it can be transformed by microorganisms such as anaerobic bacteria that facilitate methylation to $\mathrm{MeHg}$. Both forms are assimilated by fungal fruiting bodies with $\mathrm{MeHg}$ occurring at up to $15 \%$ of the total $\mathrm{Hg}(\mathrm{THg})$ content in some species, according to some sources (Kalač and Svoboda 2000).

Other elements also occur in mushrooms as previously mentioned, and in the context of $\mathrm{Hg}$ and $\mathrm{MeHg}$ toxicity, the co-occurrence of selenium (Se) is of particular interest, because of the long-reported "protective" effect of its biochemical forms, against $\mathrm{MeHg}$ toxicity. In effect, $\mathrm{MeHg}$ which is normally found in kinetically labile bonds to thiols in cerebral tissues is promiscuously capable of scavenging Se from selenoproteins that are functional in reversing and preventing oxidative damage in these tissues (Ralston and Raymond 2018). This targeted binding compromises the biological functions performed by selenium compounds, but the resulting depletion of Se compounds in the brain can be balanced by mobilizing reserves from other tissues, providing that the affected subject's diet can support the required balance with Se-rich foods. Alternatively, supplemental Se could be administered to counter the adverse consequences of high MeHg levels by supporting essential brain selenoenzyme activities. Clearly, it would be beneficial to know the $\mathrm{Hg}$-Se balance in mushroom species that are consumed, either as medicinal products or perhaps more particularly for species that are foraged in the wild, either out of necessity or for recreational purposes. It may even inform risk management strategies in areas with elevated mercury backgrounds or in regions that show Se deficiencies in the diet (Wassowicz et al. 2003).

The amount of published data on the mineral contents of fungi continues to increase, but little is known about how the distribution varies within the morphological parts, or how this distribution changes during the developmental stages; indeed some of the scarce available information is contradictory (Hinneri 1975; Falandysz et al. 2019 and Falandysz et al. 2020; Melgar et al. 2009; Thomet et al. 1999; Komárek et al. 2007; Lavola et al. 2011; Nasr et al. 2012).

Mercury occurs in higher concentration in caps than stipes of the fruiting bodies and is largely concentrated in hymenophore-gills and tubes (Falandysz et al. 2007b; Melgar et al. 2009; Kavčič et al. 2019; Seeger et al. 1976). 
The metallic and metalloid elements such as Ag, As, Cd, Cs, $\mathrm{Cu}, \mathrm{Fe}, \mathrm{Hg}, \mathrm{K}, \mathrm{Mg}, \mathrm{Rb}$, Se, and $\mathrm{Zn}$ are favorably distributed in caps and $\mathrm{Cr}, \mathrm{Na}, \mathrm{Li}, \mathrm{Cr}$, and $\mathrm{U}$ in stipes of fruiting bodies, while $\mathrm{Ba}, \mathrm{Co}, \mathrm{Ni}, \mathrm{Pb}, \mathrm{Sr}, \mathrm{Tl}$, and $\mathrm{V}$ shows an equal distribution between morphological parts of A. muscaria, but this may be influenced by some site-specific geochemical conditions of the soil substrata which can be mirrored in the BCF values for the sites (Drewnowska et al. 2013; Falandysz et al. 2007a, Falandysz et al. 2020; Lipka et al. 2018; Lipka and Falandysz 2017).

In an attempt to clarify $\mathrm{Hg}$ and Se occurrences, this study investigated different developmental stages of the fruiting bodies of A. muscaria. This species occurs commonly in the forests of Europe during the late summer and autumn months along with others edibles such as B. edulis, Leccinum spp., and others including the invasive Aureoboletus projectellus (Murrill) Halling (previous name Boletus projectellus) occurring in large numbers in recent years in Poland and which are preferred by mushroom foragers and recreational pickers. The resulting abundance of unpicked A. muscaria allows expedient collection of specimens in different stages of development.

\section{Materials and methods}

\section{Sampling}

The sampling area was located in the Kolbudy forest District (including Pomlewo village and surroundings) which is part of the rural Przywidz commune in Pomeranian Voivodeship, Poland. The forest contains mixed growths of deciduous and coniferous trees which are a typical habitat of A. muscaria. Forest cover was dominated by young, downy birch (Betula pubescens Ehrh.) interspersed with Scots pine (Pinus sylvestris L.) and Norway spruce (Picea abies (L.) H.Karst.).

In order to minimize any temporal effects, all of the specimens of A. muscaria were collected in a single morning in late September 2015, within a few hours of each other. There was good availability, and only fruiting bodies in excellent condition were selected. Immediately at the site of collection, the mushrooms were freed from forest floor litter and other debris, using a plastic knife. After collection, the fruiting bodies were separated by visual examination into six groups that reflected their stage of development with class 1 containing the youngest and class 6 containing the most mature specimens. The numbers of specimens within a group varied from 16 to 54 individuals.

Class 1 was made up of 54 specimens with the smallest fruiting bodies (button stage).Class 2 contained 27, and class 3 , an intermediate stage of development, was the smallest pool with 16 individuals. Class 4 and class 5 contained 30 and 22 individuals, respectively, and class 6 which consisted of fully mature specimens was made up of 32 individuals (Fig. 1). The

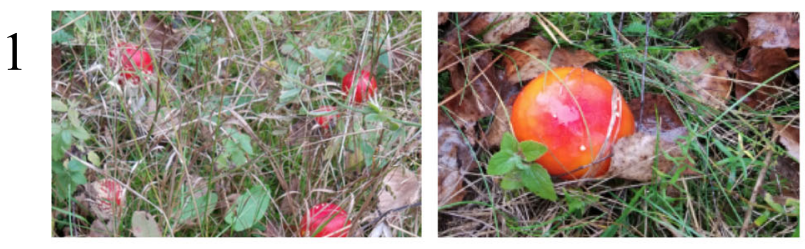

2

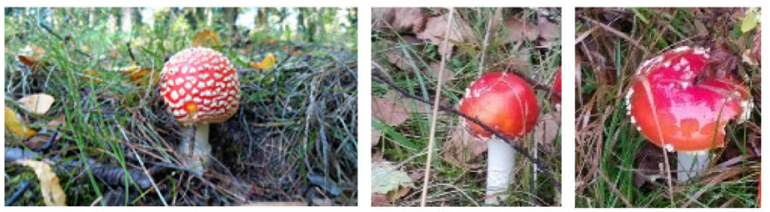

3
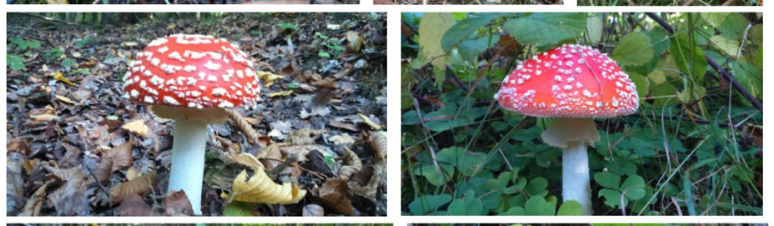

4
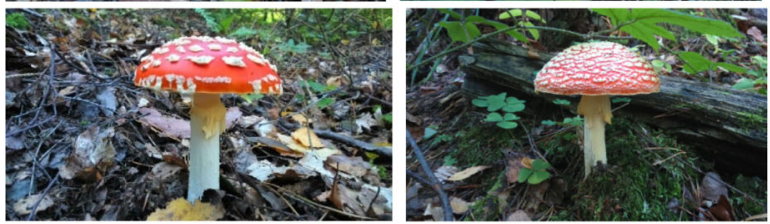

5

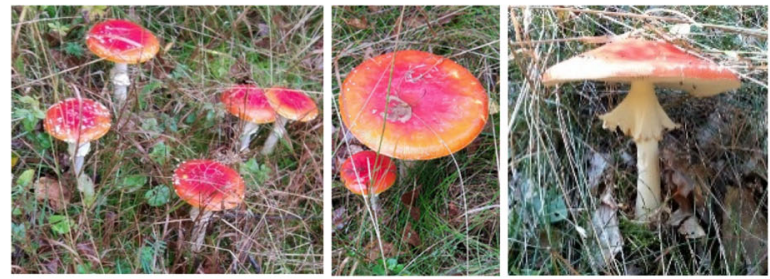

6

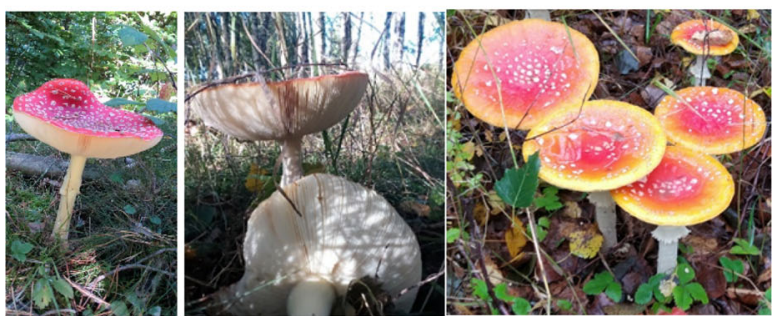

Fig. 1 The six developmental stages of A. muscaria from button to mature, sampled in this study (color for online publication only)

caps and stipes within each group were separated and pooled accordingly.

\section{Sample preparation}

Individual pooled groups were dried separately to a constant mass at $65^{\circ} \mathrm{C}$. The dried material was individually ground to a very fine powder using a blender with a glass jar and ceramic blades. The blender was cleaned between each group in order to minimize cross contamination. The pulverized samples were deposited in polyethylene bags that were sealed and placed into larger polyethylene bags which were stored in the laboratory's sample depository under dry and clean conditions at room temperature, until further analysis. 


\section{Analysis and quality control}

Analysis of the collected samples was carried out using microwave-assisted acid digestion of dried sample material followed by measurement using cold vapor atomic absorption spectroscopy (CV-AAS) in the case of $\mathrm{Hg}$ and inductively coupled plasma mass spectrometry (ICP-MS) for Se. Procedural blanks and a reference material were included in analyses to order to ensure reliability and confidence in the generated data. In the immediate period before analysis, the batch of fungal materials was dried for $12 \mathrm{~h}$ at $65^{\circ} \mathrm{C}$ using an electrically heated laboratory oven. Around $10-20 \mathrm{mg}$ aliquots of the dried material was taken for direct $\mathrm{Hg}$ determination, whilst for Se (and other elements), around $500 \mathrm{mg}$ aliquots was used. These were weighed into PTFE containers and digested in a $5-\mathrm{mL}$ solution of concentrated nitric acid (Suprapure, 65\%, Merck, Germany) using a pressureassisted microwave digestion system, along with three batch procedural blanks. The resulting solutions were transferred to pre-marked acid-clean plastic tubes and diluted to $10 \mathrm{~mL}$ with deionized water $(18 \mathrm{M} \Omega-\mathrm{cm})$ (TKA Smart2Pure, Niederelbert, Germany).

The Hg content was determined using CV-AAS (MA-2000 mercury analyzer-Nippon Instruments Corporation, Takatsuki, Japan) by direct sample thermal decomposition combined with a gold wool trap and amalgamation of $\mathrm{Hg}$ vapor and $\mathrm{Hg}$ desorption. The element was quantitatively determined at a wavelength of $253.7 \mathrm{~nm}$ with instrument operation in both high ( 25 to $150 \mathrm{ng} \mathrm{Hg}$ per sample) and low (3 to $20 \mathrm{ng} \mathrm{Hg}$ per sample) modes. Calibration curves were prepared by injecting $1.0 \mathrm{mg} \mathrm{mL}^{-1} \mathrm{Hg}$ standard solutions of 25 , $50,100,150$, and $200 \mu \mathrm{L}$ (high mode) and 3, 5, 10, 15, and 20 $\mu \mathrm{L}$ (low mode). The reference materials (Table 1) were prepared and examined in the same way.

Table 1 Assigned and determined and results on the trace element concentrations in biological control materials $\left(\mathrm{mg} \mathrm{kg}^{-1} \mathrm{dw}\right)(\mathrm{n}=3)$

\begin{tabular}{|c|c|c|c|c|}
\hline \multirow[t]{3}{*}{ Element } & \multicolumn{4}{|c|}{ Control material* } \\
\hline & \multicolumn{2}{|l|}{ CM CS-M-3 } & \multicolumn{2}{|l|}{ CRM CS-M-4 } \\
\hline & Assigned & Determined & Assigned & Determined \\
\hline $\mathrm{Hg}$ & $2.849 \pm 0.104$ & $2.759 \pm 0.075$ & $0.463 \pm 0.024$ & $\begin{array}{l}0.438 \\
\quad \pm 0.031^{\#}\end{array}$ \\
\hline $\mathrm{Se}$ & $16.21 \pm 0.85$ & $17.43 \pm 1.36$ & $1.29 \pm 0.08$ & $1.29 \pm 0.03$ \\
\hline
\end{tabular}

Notes: *Control reference materials: CM CS-M-3 (dried mushroom powder Boletus edulis) and CM CS-M-4 (dried mushroom powder Leccinum scabrum) - produced by the Institute of Nuclear Chemistry and Technology, Warsaw, Poland; WD (without data); ${ }^{~}(\mathrm{n}=11)$
Selenium was determined using ICP-MS, on an ELAN DRC II ICP-MS inductively coupled plasma mass spectrometer (PerkinElmer, SCIEX, Canada). The instrument was equipped with a Meinhard concentric nebulizer, cyclonic spray chamber, dynamic reaction cell, Pt cones, and a quadruple mass analyzer and operated using the dynamic reaction cell (DRC). The DRC consists of an enclosed quadrupole analyzer that is located between the ion lens system and the main analyzing quadrupole. The use of this technology reduces most polyatomic interferences to near background levels, which provides a significant improvement in detection limits. The instrument was operated in multi-elemental mode, and in addition to Se, a number of other elements were also determined. Calibration curves using standard solutions $\left(0.1 \mu \mathrm{g} \mathrm{L}^{-1}\right.$ to $\left.100 \mu \mathrm{g} \mathrm{L}^{-1}\right)$ were constructed in a similar manner to the $\mathrm{Hg}$ determination.

The fungal materials were analyzed in duplicate (Se) and triplicate $(\mathrm{Hg})$ for confirmation of concentration. The analytical methodology has been fully validated and reported earlier (Falandysz et al. 2015 and Falandysz et al. 2020) after peer review. The quality of measurement was continually assessed and controlled during the period of analysis using freshly prepared standard solutions, routine instrument calibration, and simultaneous analysis of the batch procedural blanks and certified materials with each analytical cycle.

\section{Results and discussion}

The concentrations of $\mathrm{Hg}$ and $\mathrm{Se}$ in the caps and stipes of composited samples of A. muscaria at the six stages of growth of the sporocarp are given in Table 2. The data are also expressed as molar $\left(\mu \mathrm{M} \mathrm{kg}^{-1} \mathrm{dw}\right)$ concentrations.

\section{Mercury occurrence in $A$. muscaria}

Examination of Table 2 shows that the $\mathrm{Hg}$ concentrations in A. muscaria ranged from 0.58 to $0.74 \mathrm{mg} \mathrm{kg}^{-1} \mathrm{dw}$ (equivalent to 2.89 to $3.69 \mu \mathrm{mol} \mathrm{kg}^{-1} \mathrm{dw}$ ) in the caps depending on the maturity stage of the fruiting body. The corresponding range for the stipes was 0.33 to $0.44 \mathrm{mg} \mathrm{kg}^{-1} \mathrm{dw}$ (1.65 to $2.19 \mu \mathrm{mol}$ $\mathrm{kg}^{-1} \mathrm{dw}$ ). This initial view of the data suggests that mercury uptake may be stable with continuous absorption by mycelia and translocation at a similar rate to stems and caps of the fruiting bodies. However, closer examination of the data by plotting $\mathrm{Hg}$ concentrations against the development stage (Fig. 2) shows similar inflections in the curves for both caps and stipes, with concentrations decreasing from the button stage to mid-growth stages before recovering again in the mature stage 6 . It is worth noting that each data point represents up to many tens of samples, with a low variability of measurement (the uncertainty is generally $\pm 0.01 \mathrm{mg} \mathrm{kg}^{-1} \mathrm{dw}$ ). The other potential source of variability in the metal content of 
Table 2 Distribution of $\mathrm{Hg}$ and Se in dehydrated A. muscaria over six stages of sporocarp development

\begin{tabular}{lllllll}
\hline Stage & Part & $\mathrm{n}$ & $\mathrm{Hg}\left(\mathrm{mg} \mathrm{kg}^{-1} \mathrm{dw}\right)$ & $\mathrm{Se}\left(\mathrm{mg} \mathrm{kg}^{-1} \mathrm{dw}\right)$ & $\mathrm{Hg}\left(\mu \mathrm{M} \mathrm{kg}^{-1} \mathrm{dw}\right)$ & $\mathrm{Se}\left(\mu \mathrm{M} \mathrm{kg}^{-1} \mathrm{dw}\right)$ \\
\hline S-1 & Cap S-1 & 54 & $0.74 \pm 0.00$ & $11 \pm 0.0$ & 3.69 & 139 \\
S-2 & Cap S-2 & 27 & $0.66 \pm 0.01$ & $9.1 \pm 0.4$ & 3.29 & 115 \\
S-3 & Cap S-3 & 16 & $0.67 \pm 0.01$ & $8.3 \pm 0.2$ & 3.34 & 105 \\
S-4 & Cap S-4 & 30 & $0.58 \pm 0.00$ & $8.6 \pm 0.2$ & 2.89 & 109 \\
S-5 & Cap S-5 & 22 & $0.62 \pm 0.01$ & $11 \pm 0.0$ & 3.09 & 139 \\
S-6 & Cap S-6 & 32 & $0.74 \pm 0.04$ & $9.8 \pm 0.3$ & 3.69 & 124 \\
& Mean, Cap & & 0.67 & 9.63 & 3.33 & 122 \\
S-1 & Stipe S-1 & 54 & $0.44 \pm 0.01$ & $4.3 \pm 0.2$ & 2.19 & 34 \\
S-2 & Stipe S-2 & 27 & $0.34 \pm 0.01$ & $2.8 \pm 0.1$ & 1.69 & 28 \\
S-3 & Stipe S-3 & 16 & $0.33 \pm 0.01$ & $2.2 \pm 0.2$ & 1.65 & 32 \\
S-4 & Stipe S-4 & 30 & $0.34 \pm 0.01$ & $2.5 \pm 0.1$ & 1.69 & 52 \\
S-5 & Stipe S-5 & 22 & $0.36 \pm 0.01$ & $4.1 \pm 0.2$ & 1.79 & 43 \\
S-6 & Stipe S-6 & 32 & $0.38 \pm 0.01$ & $3.4 \pm 0.2$ & 1.89 & 41 \\
& Mean, Stipe & & 0.37 & 3.22 & 1.82 & \\
\hline
\end{tabular}

the fruiting bodies - the soil and substrate was also minimized in this study by collecting all specimens from the same rural location without active sources of pollution, at the same time. Thus, the concentrations measured for each development stage are likely to be reliable estimates of the elemental contents. The differences observed suggest that although mycelial uptake of mercury remains constant, the weight gain during the early stages of rapid growth of the sporocarp may dilute the $\mathrm{Hg}$ concentrations in intermediate, immature specimens, before the concentration recovers in the mature stage. The lower concentrations in the stipes have been reported in other studies (Drewnowska et al. 2013) and occur at all development stages with a cap to stipe concentration quotient $\left(\mathrm{Q}_{\mathrm{C} / \mathrm{S}}\right)$ of 1.8 which is the same as that reported earlier by Drewnowska et al. (2013). This is consistent with the functionality of the stipes which consist of sterile hyphal tissue that

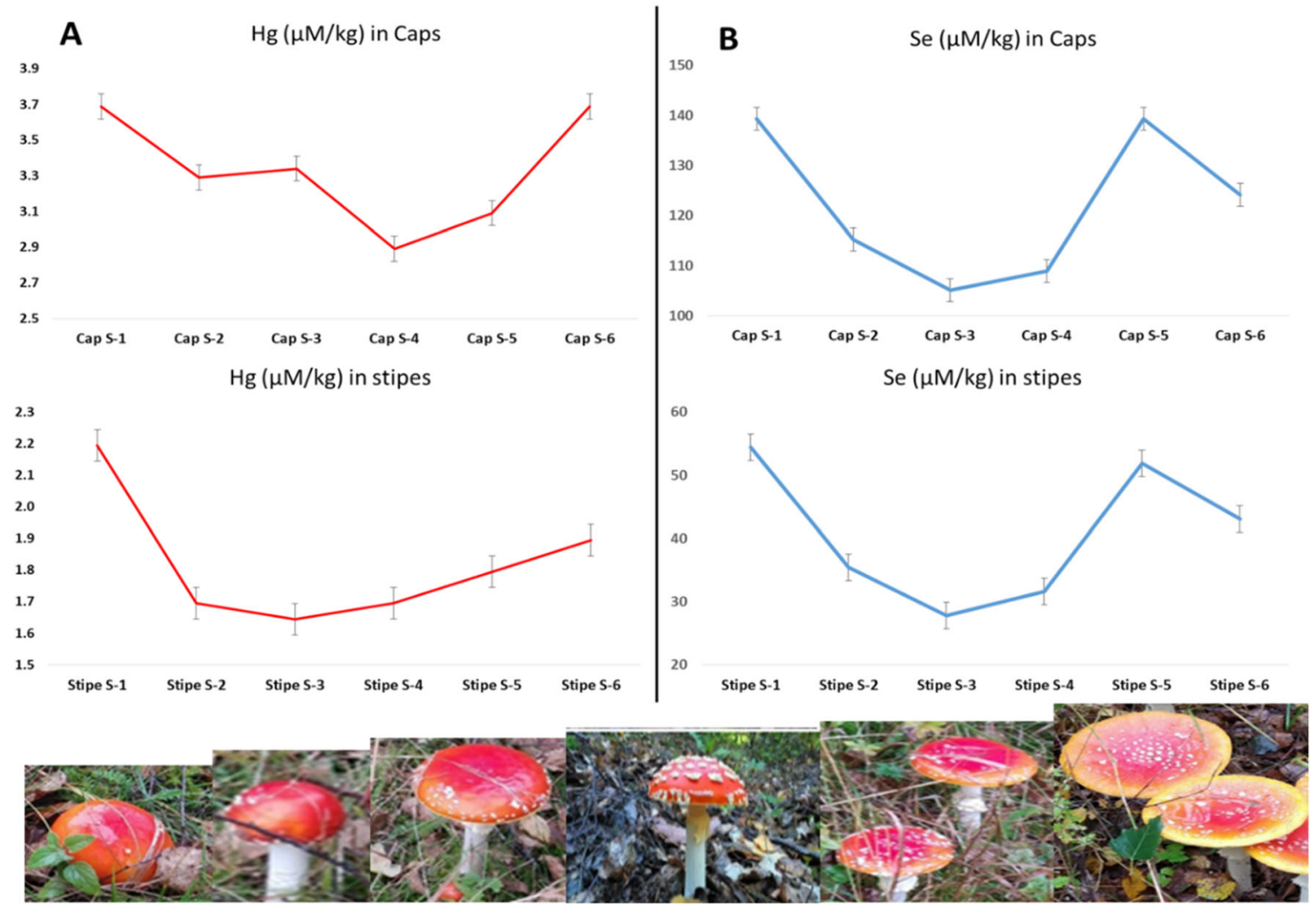

Fig. 2 Molar concentrations of $\mathrm{Hg}(\mathbf{A})$ and $\mathrm{Se}(\mathbf{B})$ in caps and stipes of A. muscaria at different developmental stages (color for online publication only) 
provides structural support and also serves to transport nutrients to the cap.

\section{Changes in selenium concentration during sporocarp development}

As an essential micronutrient, Se concentrations in the same composite samples of A. muscaria were approximately an order of magnitude greater than $\mathrm{Hg}$, and depending on the stage of development, ranged from 8.3 to $11.0 \mathrm{mg} \mathrm{kg}^{-1} \mathrm{dw}$ (equivalent to 105 to $139 \mu \mathrm{mol} \mathrm{kg}^{-1} \mathrm{dw}$ ) in the caps and 2.2 to $4.3 \mathrm{mg} \mathrm{kg}^{-1} \mathrm{dw}$ (equivalent to 28 to $54 \mu \mathrm{mol} \mathrm{kg}^{-1} \mathrm{dw}$ ) in the stipes. Analogous plotting of the data (Fig. 2B) reveals very identical curve shapes for both the caps and the stipes. These shapes suggest a similar depletion of Se in caps and stipes during the first stages of growth before recovery to initial button stage concentrations by stage 5 . However, unlike the curves for $\mathrm{Hg}$, the Se concentrations drop again, by similar proportions in both caps and stipes (11\% in the caps and $17 \%$ in the stipes). Unlike mercury which is not known to serve any function in mushrooms, Se is functional and exists as several organic selenium-containing amino acids such as selenocysteine, selenomethionine, Se-methylselenocysteine in selenium-dependent enzymes (selenoenzymes/ selenoproteins), selenite and several other unidentified seleno-compounds in widely varying proportions depending on the mushrooms species (Falandysz 2008, 2013). The amino acids such as selenocysteine are reported to serve known or predicted oxidoreductase functions (Mariotti et al. 2018). It is not currently known whether the maturing and dispersal of spores during the final stage makes a greater demand on seleno-compounds corresponding to the reduction observed in the mature (stage 6) group. Given the similarity of the plotted curves for Se in the caps and stipes, it is unsurprising that there is good correlation of Se content at different development stages, with a correlation coefficient of 0.996 .

\section{Comparative profile}

There are only a handful of other studies that have investigated $\mathrm{Hg}$ and or Se in A. muscaria including samples from Poland (Table 3) (Falandysz et al. 2007a, b; Stijve 1977; Watkinson 1964). In the first study of Se in A. muscaria, two specimens from New Zealand showed Se in concentrations of 16.8 and $17.8 \mathrm{mg} \mathrm{kg}^{-1} \mathrm{dw}$ (Watkinson 1964). In a study published in 1977 by Stijve (1977), specimens collected near Lake Geneva in Switzerland showed a Se concentration of $2.90\left(\mathrm{mg} \mathrm{kg}^{-1} \mathrm{dw}\right.$ (range 1.37-4.84; $\mathrm{n}=3$ ). The Se distribution between fleshy parts in pools of 15 did not differ between caps $\left(3.96 \mathrm{mg} \mathrm{kg}^{-1}\right.$ $\mathrm{dw}$ ) and lamellae $\left(4.04 \mathrm{mg} \mathrm{kg}^{-1} \mathrm{dw}\right)$ but was lower in the stipes at $1.23 \mathrm{mg} \mathrm{kg}^{-1} \mathrm{dw}$ (Stijve 1977). The concentration of $\mathrm{Hg}$ in the caps ranged from $0.17 \mathrm{mg} / \mathrm{kg}$ for a composite sample collected from the Bydgoszcz area of North Central
Poland in 2000 to $0.79 \mathrm{mg} \mathrm{kg}^{-1} \mathrm{dw}$ for a similar composite harvested in the Masuria region. The corresponding range for the stipes was 0.18 to $0.51 \mathrm{mg} \mathrm{kg}^{-1} \mathrm{dw}$ also for the Masuria region. The average data from the current study are similar to those for the sample collected from the Masuria region in 1999. The current study showed the highest cap concentrations for Se compared to the literature data, which ranged from 4.1 to $9.8 \mathrm{mg} \mathrm{kg}^{-1} \mathrm{dw}$ (stipe concentration range- 1.4 to $4.7 \mathrm{mg} \mathrm{kg}^{-1} \mathrm{dw}$ ). The data from these studies has been summarized in Table 3, although not all studies included separate measurements for caps and stipes.

The uptake of non-essential elements such as mercury in mushrooms is in many ways dependent on the abundance of these elements in the substrate in which they grow, which is in turn dependent on the proximity to sources. Other dependent variables are the species of mushroom and the age of the fruiting bodies and mycelia. However, some species (e.g., Clitocybe, Agaricus, Lepista, Boletus) show a tendency to bio-accumulate elements like $\mathrm{Hg}$ even if the substrate is not particularly rich in this element (Falandysz et al. 2002). The uptake of other chalcophile elements (surficial elements that associate with sulfur) in A. muscaria at different stages of development was recently described (Falandysz et al. 2020). The data indicates variability with uptake depending on the element. The concentrations of some elements such as cadmium $(\mathrm{Cd})$ and silver $(\mathrm{Ag})$ remain broadly unchanged over the different stages of development, but the concentration of others such as lead $(\mathrm{Pb})$ and antimony $(\mathrm{Sb})$ halves as the sporocarp develops from button stage to maturity $(0.11$ to $0.062 \mathrm{mg} \mathrm{kg}^{-1} \mathrm{dw}$ for $\mathrm{Pb}$ and 0.013 to $0.006 \mathrm{mg} \mathrm{kg}^{-1} \mathrm{dw}$ for $\mathrm{Sb})$.

\section{Relative occurrence of $\mathrm{Hg}$ and Se-implication for consumers}

Although the relative proportions vary depending on species, the caps of A. muscaria generally contain higher concentrations of metallic and metalloid elements (Falandysz et al. 2020) than the stipes except for some elements ( $\mathrm{Pb} \mathrm{Al}, \mathrm{Ni}$, $\mathrm{Sr}$, and uranium). Both $\mathrm{Hg}$ and Se occur to a greater proportion in the caps, but while the molar ratio of $\mathrm{Hg}$ in cap:stipe remains more or less constant (generally $1.8 \pm 0.1$ ), the ratio for Se varies to a greater extent and is highest during stages 24 of development. This may relate to a greater demand for seleno-compounds in the caps during these stages of development. The caps of A. muscaria has been reported to contain higher concentrations of a number of amino acids such as isoleucine, leucine, valine, alanine, aspartate, asparagine, and threonine, and lipids such as glycerol, choline, and glycerophosphocholine compared to the stipes (Deja et al. 2014).

Although both inorganic and alkylated forms of $\mathrm{Hg}$ have been demonstrated to be cytotoxic to neural cells in animals, 
Table 3 Summary of $\mathrm{Hg}$ and Se concentrations $\left(\mathrm{mg} \mathrm{kg}^{-1} \mathrm{dw}\right)$ from literature studies on A. muscaria.

\begin{tabular}{|c|c|c|c|c|c|}
\hline Location & No. samples & Part & $\mathrm{Hg}\left(\mathrm{mg} \mathrm{kg}^{-1} \mathrm{dw}\right)$ & $\operatorname{Se}\left(\mathrm{mg} \mathrm{kg}^{-1} \mathrm{dw}\right)$ & Reference \\
\hline \multirow[t]{2}{*}{ This study, Pomerania, Poland } & \multirow[t]{2}{*}{32} & Cap & 0.74 & 9.8 & - \\
\hline & & Stipe & 0.38 & 3.4 & - \\
\hline New Zealand & 2 & Whole & - & $16.8-17.8$ & Watkinson 1964 \\
\hline \multirow[t]{2}{*}{ Near Lake Geneva, Switzerland } & \multirow[t]{2}{*}{15} & Cap & - & 3.96 & \multirow[t]{2}{*}{ Stijve 1977} \\
\hline & & Stipe & - & 1.23 & \\
\hline \multirow[t]{2}{*}{ Morag, Poland } & \multirow[t]{2}{*}{15} & Cap & 0.35 & 4.6 & \multirow[t]{6}{*}{ Falandysz et al. 2007} \\
\hline & & Stipe & 0.18 & 1.4 & \\
\hline Giżycko, Poland & 15 & Cap & 0.32 & 5 & \\
\hline Bydgoszcz, Poland & 14 & Cap & 0.17 & 4.1 & \\
\hline Masuria, Poland & 15 & Stipes & 0.35 & 4.7 & \\
\hline Pomerania, Poland & & Stipes & 0.25 & 4.4 & \\
\hline \multirow[t]{2}{*}{ Masuria, Poland 1999} & \multirow[t]{2}{*}{15} & Cap & 0.79 & - & \multirow[t]{2}{*}{ Drewnowska et al. 2013} \\
\hline & & Stipe & 0.51 & - & \\
\hline
\end{tabular}

the potency of the methylated species is far greater (Tong et al. 2016). In exposed humans, $\mathrm{MeHg}$ represents around $40 \%$ on average, of the THg content of blood (Carneiro et al. 2014) and correlates to a greater extent with adverse effects than inorganic Hg. Although the foods that are most prone to $\mathrm{MeHg}$ contamination are those derived from animal and particularly aquatic/marine sources-microorganism-mediated conversion of $\mathrm{Hg}$ to methylated forms makes this bioavailable and then bio-concentrated up the marine food web-human exposure will of course depend on individual food preferences and/or availability of different foods. The high consumption rates of fungal species that are foraged by certain populations have been reported before (Zhang et al. 2010), and although edible mushroom species may not contain as high THg levels as fish, the frequency and amounts of consumption may make a significant contribution to an individual's intake of $\mathrm{Hg}$. The co-occurrence of $\mathrm{Se}$ with $\mathrm{Hg}$ in the flesh of mushrooms is therefore of considerable significance to consumers, because of the mitigating potential that existing seleno-compounds have on the detrimental health effects of $\mathrm{Hg}$. The large (approximately one order of magnitude) excess of Se relative to $\mathrm{Hg}$ observed in A. muscaria in this study is therefore of benefit to consumers. However, there are a number of unknowns, when consumed for nutritional purposes; A. muscaria will have been processed by boiling in water (which is discarded, in order to eliminate the hallucinogens, muscimol, ibotenic acid, etc.) and possibly further pickled before consumption as seen in some cultures (Phipps et al. 2000).

Mushrooms vary considerably in content of Se and many edible wild species have Se at level below $1 \mathrm{mg} \mathrm{kg}^{-1} \mathrm{dw}$, while certain from the family Boletaceae are Se-rich with levels exceeding $10 \mathrm{mg} \mathrm{kg}^{-1} \mathrm{dw}$ (Costa-Silva et al. 2011; Falandysz 2008; Falandysz 2013). The white button mushroom
Agaricus bisporus (champignon), which is the most popular cultivated edible mushroom and when raw had around 1 to $2 \mathrm{mg}$ of Se per $\mathrm{kg}^{-1} \mathrm{dw}$ (Costa-Silva et al. 2011; Pankavec et al. 2019), and pickled products had $0.60 \mathrm{mg} \mathrm{kg}^{-1} \mathrm{dw}$ (median; and medians in the range from 0.19 to $1.6 \mathrm{mg} \mathrm{kg}^{-1} \mathrm{dw}$ (Pankavec et al. 2019). Thus, eating mushrooms also has value for Se intake to reduce Se deficiency and including inhabitants in Se-depleted zones, while this aspect is worth further research.

These processes (blanching/pickling) are known to leach out both contaminants such as $\mathrm{Hg}$ and nutritionally beneficial elements such as potassium, copper, and zinc (Drewnowska et al. 2017a, 2017b). Clearly this would also potentially result in the loss of selenium, although the extent and proportion of this loss relative to $\mathrm{Hg}$ are not currently known (as $\mathrm{Se}$ in mushrooms is in the form of Se-organic molecules and in a little portion is in insoluble HgSe complexes (Falandysz 2008; Kavčič et al. 2019)). Additionally, a proportion of the THg in A. muscaria would occur as MeHg. This proportion is currently known from one study and limited in a number of specimens $(n=3)$ examined and was as 0.40 to $0.90 \%$ (Fischer et al. 1995). However, as a constituent associated with proteins (Charette et al. 2021), MeHg and Se in selenoproteins may not be lost to the same extent as inorganic $\mathrm{Hg} / \mathrm{Se}$ by aqueous processing such as boiling. These considerations are likely to apply to all edible fungal species.

\section{Conclusions}

The data from this study was derived from A. muscaria specimens that were collected in excellent condition during a very short timeframe from the same location. Combined with generally large numbers of individual samples per development 
stage composite, and low uncertainty of measurement, the data are likely to be representative of the typical concentrations of $\mathrm{Hg}$ and $\mathrm{Se}$ in the studied development stages of this species. Hg and Se levels were observed to vary during the developmental stages and the variability may relate to the demands in growth. Both $\mathrm{Hg}$ and Se levels were lowest during periods of maximum growth of the sporocarp. In common with some other mushroom species, the stipes contained lower concentrations of both elements, which is consistent with the functionality of the stipes as a transport and supporting structure.

Selenium occurs at almost an order of magnitude greater levels than $\mathrm{Hg}$. Due to its role in mitigating the effects of $\mathrm{Hg}$ toxicity, this property is of significance to those who consume the species either for nutritional, medicinal, or recreational purposes, although the losses of both these elements during processing are not known.

\section{Availability of data and materials Not applicable.}

Authors' contributions Methodology, investigation, validation, formal analysis, data curation, review and editing: Anetta Hanć. Conceptualization, data curation, visualization, writing — original draft preparation-review and editing: Alwyn R. Fernandes. Conceptualization, methodology, formal analysis, investigation, resources, data curation, visualization, review and editing, supervision: Jerzy Falandysz. Investigation, data curation, review and editing: Ji Zhang.

\section{Declarations}

Ethical approval This article does not contain any studies with human participants or animals performed by any of the authors.

Consent to participate Not applicable. This manuscript does not contain any studies with human participants or animals performed by any of the authors.

Consent to publish Not applicable. This manuscript does not contain any individual person's data in any form.

Conflict of interest The authors declare that they have no conflict of interest.

Open Access This article is licensed under a Creative Commons Attribution 4.0 International License, which permits use, sharing, adaptation, distribution and reproduction in any medium or format, as long as you give appropriate credit to the original author(s) and the source, provide a link to the Creative Commons licence, and indicate if changes were made. The images or other third party material in this article are included in the article's Creative Commons licence, unless indicated otherwise in a credit line to the material. If material is not included in the article's Creative Commons licence and your intended use is not permitted by statutory regulation or exceeds the permitted use, you will need to obtain permission directly from the copyright holder. To view a copy of this licence, visit http://creativecommons.org/licenses/by/4.0/.

\section{References}

Carneiro MFH, Grotto D, Barbosa F Jr (2014) Inorganic and methylmercury levels in plasma are differentially associated with age, gender, and oxidative stress markers in a population exposed to mercury through fish consumption. J Toxicol Environ Health A 77:69-79

Charette T, Rosabal M, Amyot M (2021) Mapping metal (Hg, As, Se), lipid and protein levels within fish muscular system in two fish species (Striped Bass and Northern Pike). Chemosphere 265: 129036

Costa-Silva F, Marques G, Matos CC, Barros AIRNA, Nunes FM (2011) Selenium contents of Portuguese commercial and wild edible mushrooms. Food Chem 126:91-96

Deja S, Wieczorek PP, Halama M, Jasicka-Misiak I, Kafarski P, Poliwoda A, Młynarz P (2014) Do differences in chemical composition of stem and cap of Amanita muscaria fruiting bodies correlate with topsoil type? PLoS One 9(12):e104084

Drewnowska M, Lipka K, Jarzyńska G, Danisiewicz-Czupryńska D, Falandysz J (2013) Investigation on metallic elements of Fly Agaric, Amanita muscaria, fungus and the forest soils from the Mazurian Lakes District of Poland. Fresenius Environ Bull 22: 455-460

Drewnowska M, Falandysz J, Chudzińska M, Hanć A, Saba M, Barałkiewicz D (2017a) Leaching of arsenic and sixteen metallic elements from Amanita fulva mushrooms after food processing. LWT Food Sci Technol 84:861-866

Drewnowska M, Hanć A, Barałkiewicz D, Falandysz J (2017b) Pickling of chanterelle Cantharellus cibarius mushrooms highly reduce cadmium contamination. Environ Sci Pollut Res 23:21733-22173

EFSA, European Food Safety Authority (2012) Panel on Contaminants in the Food Chain (CONTAM). Scientific Opinion on the risk for public health related to the presence of mercury and methylmercury in food. EFSA J 10:2985

Falandysz J (2008) Selenium in edible mushrooms. J Environ Sci Health Part C 26:256-299

Falandysz J (2013) Review: On published data and methods for selenium in mushrooms. Food Chem 138:242-250

Falandysz J, Bielawski K, Kawano M, Brzostowski A, Chudzyński K (2002) Mercury in mushrooms and soil from the Wieluńska Upland in South-Central Poland. J Environ Sci Health Part A - Toxic/ Hazard Subs Environ Engine 37:1409-1420

Falandysz J, Kunito T, Kubota R, Lipka K, Mazur A, Falandysz JJ, Tanabe S (2007a) Selected elements in fly agaric Amanita muscaria. J Environ Sci Health Part A 42:1615-1623

Falandysz J, Lipka K, Mazur A (2007b) Mercury and its bioconcentration factors in fly agaric (Amanita muscaria) from spatially distant sites in Poland. J Environ Sci Health Part A 42:1625-1630

Falandysz J, Zhang J, Wang Y, Saba M, Krasińska G, Wiejak A, Li T (2015) Evaluation of the mercury contamination in fungi Boletus species from latosols, lateritic red earths, and red and yellow earths in the Circum-Pacific Mercuriferous Belt of Southwestern China. PLoSONE 10(11): e0143608. https://doi.org/10.1371/journal.pone. 0143608

Falandysz J, Saniewski M, Zalewska T, Zhang J (2019) Pollution by radiocaesium of fly agaric Amanita muscaria in fruiting bodies decrease with a developmental stage. Isot Environ Sci Health 55:317324

Falandysz J, Hanć A, Barałkiewicz D, Zhang J, Treu R (2020) Metallic and metalloid elements in various developmental stages of Amanita muscaria (L.) Lam. Fungal Biol 124:174-182

Fischer RG, Rapsomanikis S, Andreae MO, Baldi F (1995) Bioaccumulation of methylmercury and transformation of inorganic mercury by macrofungi. Environ Sci Technol 29:993-999

Guzmán G (2008) Diversity and use of traditional Mexican medicinal fungi. A review. Int J Med Mushrooms 10:209-217 
Hawkeswood TJ (2006) A record of Amanita muscaria (L.) Lam. (Basidiomycetes: Amanitaceae) from Wentworth Falls, New South Wales, Australia with a review of some literature on the ecology of the species within Australia. Calodema 7:29-31

Hinneri S (1975) Mineral elements of macrofungi in oak-rich forests on Lenholm island, inner archipelago of SW Finland. Ann Bot Fenn 12:135-140

Kalač P, Svoboda L (2000) A review of trace element concentrations in edible mushrooms. Food Chem 69:273-281

Kavčič A, Mikuš K, Debeljak M, van Elteren JT, Arčon I, Kodre A, Kump P, Karydas AG, Migliori A, Czyżycki M, Vogel-Mikuš K (2019) Localization, ligand environment, bioavailability and toxicity of mercury in Boletus spp. and Scutiger pes-caprae mushrooms. Ecotoxicol Environ Saf 184:109623

Komárek M, Chrastný V, Štichová J (2007) Metal/metalloid contamination and isotopic composition of lead in edible mushrooms and forest soils originating from a smelting area. Environ Intern 13: 677-684

Lavola A, Aphalo PJ, Lehto T (2011) Boron and other elements in sporophores of ectomycorrhizal and saprotrophic fungi. Mycorrhiza 21: $155-165$

Lipka K, Falandysz J (2017) Accumulation of metallic elements by Amanita muscaria from rural lowland and industrial upland regions. J Environ Sci Health Part B 52:184-190

Lipka K, Saba M, Falandysz J (2018) Preferential accumulation of inorganic elements in Amanita muscaria from North-eastern Poland. J Environ Sci Health Part A 53:968-974

Luo Z-B, Wu Ch, Zhang Ch, Li H, Lipka U, Polle A (2014) The role of ectomycorrhizas in heavy metal stress tolerance of hostplants. Environ Exp Bot 108:47-62

Mariotti M, Salinas G, Gabaldon T, Gladyshev V (2018) Use of selenocysteine, the $21 \mathrm{st}$ amino acid, in the fungal kingdom. Biorxiv. https://doi.org/10.1101/314781

Melgar MJ, Alonso J, Garcia MÁ (2009) Mercury in edible mushrooms and soil: Bioconcentration factors and toxicological risk. Sci Total Environ 407:5328-5334

Nasr M, Arp PA (2011) Hg concentrations and accumulations in fungal fruiting bodies, as influenced by forest soil substrates and moss carpets. Appl Geochem 26:1905-1917

Nasr M, Malloch DW, Arp PA (2012) Quantifying Hg within ectomycorrhizal fruiting bodies, from emergence to senescence. Fungal Biol 116:1163-1177

Pankavec S, Hanć A, Barałkiewicz D, Dryżałowska A, Zhang J, Falandysz J (2019) Mineral constituents of conserved white button mushrooms: Similarities and differences. Roczn Państw Zakł Hig $71: 15-25$

Phipps AG, Bennett BC, Downum KR (2000) Japanese use of Benitengu-dake (Amanita muscaria) and the efficacy of traditional detoxification methods. Florida International University, Miami, Florida

Ralston N, Raymond L (2018) Mercury's neurotoxicity is characterized by its disruption of selenium biochemistry, Biochim Biophys. Acta Gen Subj 1862:2405-2416

Rubel W, Arora D (2008) A study of cultural bias in field guide determinations of mushroom edibility using the iconic mushroom, Amanita muscaria, as an example. Econ Bot 62:223-243

Seeger R (1976) Quecksilbergehalt der Pilze. Z Lebensm Unters-Forsch $160: 303-312$

Seeger R, Nūtzel R, Feulner L (1976) Die Verteilung des Quecksilbers in den Fruchtkörpern von Steinpilzen und Champignons. Z Lebensm Unters-Forsch 161:115-117

Stijve T (1977) Selenium content of mushrooms. Z Lebensm UntersForsch 164(201):203

Thomet U, Vogel E, Krähenbühl U (1999) The uptake of cadmium and zinc by mycelia and their accumulation in mycelia and fruiting bodies of edible mushrooms. Eur Food Res Technol 209:317-324

Tong J, Wang Y, Lu Y (2016) In vitro evaluation of inorganic and methyl mercury mediated cytotoxic effect on neural cells derived from different animal species. J Environ Sci 41:138-145

van der Heijden MGA, Martin F, Selosse M-A, Sanders IR (2015) Mycorrhizal ecology and evolution: the past, the present, and the future. New Phytol 205:1406-1423

Wąsowicz W, Gromadzińska J, Rydzyński K, Tomczak J (2003) Selenium status of low-selenium area residents: Polish experience. Toxicol Lett 137:95-101

Watkinson JH (1964) A selenium-accumulating plant of the humid regions: Amanita muscaria. Nature 202:1239-1240

Yun W, Hall I (2004) Edible ectomycorrhizal mushrooms: challenges and achievements. Can J Bot 82:1063-1107

Zhang D, Frankowska A, Jarzyńska G, Kojta AK, Drewnowska M, Wydmańska D, Bielawski L, Wang J, Falandysz J (2010) Metals of King Bolete (Boletus edulis) Bull.: Fr. collected at the same site over two years. Afr J Agric Res 5:3050-3055

Publisher's note Springer Nature remains neutral with regard to jurisdictional claims in published maps and institutional affiliations. 